\title{
Comparison of li-ion battery ageing models applied in photovoltaic stand-alone systems
}

\author{
R. Dufo-López, S. Marquino Leonar, J.L. Bernal-Agustín, J.S. Artal-Sevil, José A. Domínguez-Navarro \\ Department of Electrical Engineering \\ EINA, University of Zaragoza. \\ C/ María de Luna, 3, 50018 Zaragoza (Spain) \\ Phone/Fax number:+0034 976761921, e-mail: rdufo@unizar.es, 602661@unizar.es, jlbernal@unizar.es,
} jsartal@unizar.es, jadona@unizar.es

\begin{abstract}
In this paper, three models to predict the ageing of li-ion batteries (LiFePO4/graphite) are compared. The models are applied in stand-alone (off-grid) photovoltaic (PV) - battery systems and PV - diesel (or gasoline) - battery systems.

A high dependency on temperature is shown for all the models: the battery degrades at a higher rate as temperature increases. Also, all the models present a dependency on the charge and discharge rate: higher degradation occurs as charge and discharge rate increases. Also degradation is highly affected by pauses in between charge and discharge steps. Most of these dependencies are coupled and highly non-linear.

In PV-battery systems the charge and discharge rate is usually low (lower than $\mathrm{C} / 2$ ), as the battery capacity is usually high (designed for several days of autonomy, usually 2-6 days). Even in PV-diesel or gasoline-battery systems this rate is low, although the battery capacity is much lower than in PV-battery systems.

The models are evaluated in systems located near Zaragoza. In all the cases a $2.4 \mathrm{kWp}$ PV generator is considered. The size of the battery bank and of the diesel or gasoline generator varies in the different cases.

All the models show high battery life ( $>30$ years) in cases of PVbattery systems (with a battery bank of 4 days autonomy). However, in the cases of PV-gasoline-battery systems, there is a great difference in the estimation of the lifetime obtained by the different models.
\end{abstract}

\section{Key words}

Li-ion battery, ageing models, photovoltaic, off-grid.

\section{Introduction}

In off-grid systems based in renewable sources, batteries are needed to supply the net load when the renewable power is not enough [1]. Almost $100 \%$ of the batteries in this kind of systems are lead-acid types. However, as the price of li-ion batteries is decreasing, it is expected that in a near future they can be competitive in this kind of systems.

The prediction of the ageing of the battery is a very important task when the designer must estimate the total cost of the system during its lifetime. Usually, the lifetime of PV-battery systems is considered the same as the PV panels lifetime, that is, 25 years. During this period the battery bank must be replaced when its lifetime ends (it is usually considered when the remaining capacity is lower than $80 \%$ of nominal capacity). The experience shows that, for lead-acid batteries, in some cases, depending on the technology of the battery, temperature, charge and discharge rate, daily energy cycled, time between full charges, and other variables, the battery bank must be replaced in a year or even in less time. In other cases, it can last 15 or 20 years [2]. Then, the estimation of the lifetime of the battery bank is crucial to know the total cost of the battery bank during the lifetime of the system (including all the repositions) and therefore the total net present cost of the system. With this estimation, the designer can estimate the cost per $\mathrm{kWh}$ of energy supplied during the lifetime of the system, and therefore the user can compare with other possibilities (systems which only include diesel or gasoline generator or hybrid systems).

There are many ageing models for lead-acid batteries, with higher or lower accuracy and complexity [2]. However, for Li-ion batteries the state-of-the-art includes just few models. In the literature review, just three models have been found for LiFePO4/graphite batteries:
1. Model shown by Wang et al., 2011 [3]
2. Model shown by Grot, 2014 [4]
3. Model shown by Grot et al., 2015 [5]

In this paper the lifetime prediction of the three models in different cases of PV-battery and PV-gasoline-battery systems is compared.

\section{LiFePO4/graphite batteries ageing models}

Next a brief explanation of the different ageing models used is shown.

\section{A. Model shown by Wang et al., 2011}

Wang et al. [3] studied the ageing of more than 25,000 LiFePO4/graphite 2.2 Ah cells by performing accelerated 
charge/discharge tests, under different conditions of temperature, depth of discharge (DOD) and charge/discharge rate (C-rate). At the low C-rates, experimental results indicated that the capacity loss was strongly affected by time and temperature, while the DOD effect was less important. Authors obtaining the percent of capacity loss (Qloss) as a function of the equivalent full cycles performed (Ah is the total Ah throughput, that is, cycle number $\times \mathrm{DOD} \times$ full cell capacity):

$Q_{\text {loss }}=30,330 \exp \left(\frac{-31,500}{8.314 T}\right) A_{\mathrm{h}}^{0.552}$

where $\mathrm{T}$ is the absolute temperature $(\mathrm{K})$. This equation was found for C/2 C-rate (i.e., full charge is obtained in 2 hours and full discharge is also obtained in $2 \mathrm{~h}$ ) and from 15 to $60^{\circ} \mathrm{C}$ temperature. Authors evaluate higher C-rates (from $\mathrm{C} / 2$ to $10 \mathrm{C}$, where $10 \mathrm{C}$ means that battery is fully charged or discharged in 1/10 hour) but they do not evaluate lower C-rates therefore this equation will be used in the cases evaluated in this paper (C-rates are usually lower than $\mathrm{C} / 2$ in stand-alone systems).

\section{B. Model shown by Grot, 2014}

This model [4] considers a cumulative degradation:

$$
C=C_{B O L} \cdot\left(1-\kappa_{L o s s, A / L}\right) C T
$$

where $\mathrm{C}$ is the remaining cell capacity (Ah), $\mathrm{C}_{\mathrm{BOL}}$ is the cell capacity at BOL (beginning of life), $\mathrm{K}_{\mathrm{LOSS}, \mathrm{A} / \mathrm{L}}$ is the LAAM (loss of anode material)/Cyclable lithium loss per complete capacity and CT is the total capacity throughput. The calculation of $\mathrm{K}_{\mathrm{LOSS}, \mathrm{A} / \mathrm{L}}$ is not trivial as it depends on many weights and factors related to state of charge (SOC), DOD, temperature, current, distribution of total capacity throughput between segments and state of health ( $\mathrm{SOH})$.

\section{Model shown by Grot et al., 2015}

The same author obtained in 2015 the following simple empirical cycle life relation for 2.3 Ah cells [5]:

$$
Q_{E O L}[\mathrm{kAh}]=\left(a \cdot e^{b \cdot I} \cdot T^{\left(c \cdot l^{2}+d \cdot I+e\right)}\right)+f
$$

where QEOL is the charge (kAh) the cell can cycle during its lifetime, i.e., until EOL (end of life), $\mathrm{I}$ is the C-rate, $\mathrm{T}$ is the temperature $\left({ }^{\circ} \mathrm{C}\right)$ and $\mathrm{a}, \mathrm{b}, \mathrm{c}, \mathrm{d}$, e and $\mathrm{f}$ are fit constants. It is valid for symmetrical cycles at $100 \%$ DOD in the studied range of temperature $\left(25-50^{\circ} \mathrm{C}\right)$ and current rate $(1$ to $3.75 \mathrm{C})$.

\section{Results}

A PV-battery system (case A) and a PV-gasoline-battery system (case B) have been analysed and their battery life prediction has been compared considering the three models previously shown. In all the cases
LiFePO4/graphite batteries are used and systems are located in Zaragoza. In all the simulations a constant cell temperature of $20^{\circ} \mathrm{C}$ has been considered. Also, in all the simulations, a maximum of 30 years have been considered for the battery lifetime.

\section{A. PV-battery system}

The system is composed by a $2.4 \mathrm{kWp} \mathrm{PV}$ generator with a battery bank of $15.2 \mathrm{kWh}$ (16 serial x 138 parallel cells of $3 \mathrm{~V}, 2.3 \mathrm{Ah}$, that is, a total of $317.4 \mathrm{Ah})$. The system includes an inverter of $900 \mathrm{~W}$. The load is of a small isolated house of $3.56 \mathrm{kWh} /$ day. Around 4 days of autonomy are achieved with that battery bank.

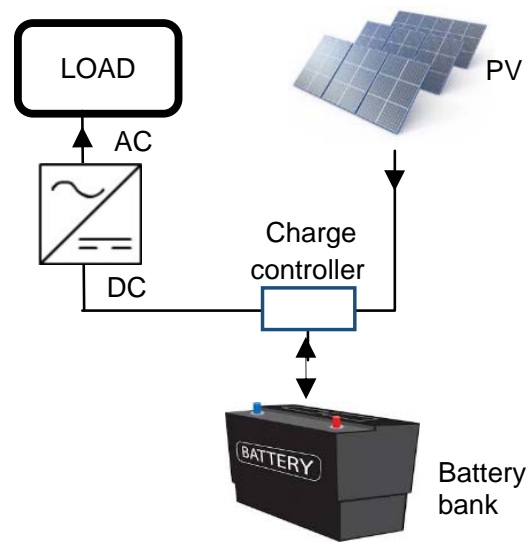

Fig. 1. PV-battery system

The results are shown in Tables I and II, case A.

Table I. Annual performance

\begin{tabular}{|c|c|c|c|c|c|}
\cline { 2 - 5 } \multicolumn{1}{c|}{} & \multicolumn{4}{c|}{ Annual energy $(\mathrm{kWh} / \mathrm{yr})$} & \multirow{2}{*}{ Annual } \\
Case & Load & PV & Diesel & Bat. Disch. & full eq. cycles \\
\hline A & 1325 & 2788 & 0 & 665 & 43 \\
\hline B1 & 1325 & 2788 & 640 & 289 & 564 \\
\hline B2 & 1325 & 2788 & 747 & 447 & 1013 \\
\hline
\end{tabular}

\begin{tabular}{|c|c|c|c|}
\hline \multirow[b]{2}{*}{ Case } & \multicolumn{3}{|c|}{$\begin{array}{l}\text { Battery lifetime (years) (until remaining } \\
\text { capacity drops to } 80 \% \text { ) }\end{array}$} \\
\hline & Wang et al. & Grot, 2014 & Grot et al., 2015 \\
\hline $\mathrm{A}$ & $>30 *$ & $>30 * *$ & $>30 * * *$ \\
\hline B1 & 18 & 10.5 & 12.8 \\
\hline B2 & 12.1 & 7.2 & 8.3 \\
\hline \multicolumn{4}{|c|}{$*(7.5 \%$ loss in 30 years $)$} \\
\hline \multicolumn{4}{|c|}{$* *(4.7 \%$ loss in 30 years $)$} \\
\hline \multicolumn{4}{|c|}{ ***(results in 132 years) } \\
\hline
\end{tabular}

Table II. Expected battery lifetime

Results show that all the models predict a very high lifetime, much higher than 30 years. However, it is 
logical to think that corrosion and other factors will limit its lifetime to a maximum of around 20 years.

\section{B. PV-gasoline-battery system}

The system is composed by a same $2.4 \mathrm{kWp}$ PV generator (with an inverter in order to connect to the AC coupled bidirectional converter) with a much lower battery bank than previous section, of 441 Wh (16 serial x 4 parallel cells of $3 \mathrm{~V}, 2.3 \mathrm{Ah}$, that is, a total of $9.2 \mathrm{Ah})$. The system includes a bidirectional converter, an inverter of $900 \mathrm{~W}$ and a gasoline generator of $1000 \mathrm{~W}$. The load is same of section A.

Two cases have been considered taking into account the control strategy of the system:

- Case B1. The control strategy used is the "Load following" strategy, that is, when the renewable sources cannot meet the whole load, the battery bank supplies the net load if its SOC is higher than a minimum value (20\%), otherwise the gasoline generator supplies it and it does not charge the battery bank (unless its minimum output power was higher than the net load, supplying the rest to the battery bank).

- Case B2. The control strategy used is the "Cycle charging” strategy, that is, when the renewable sources cannot meet the whole load, the battery bank supplies the net load if its SOC is higher than a minimum value (20\%), otherwise the gasoline generator supplies it and also charges the battery bank until it is fully charged.

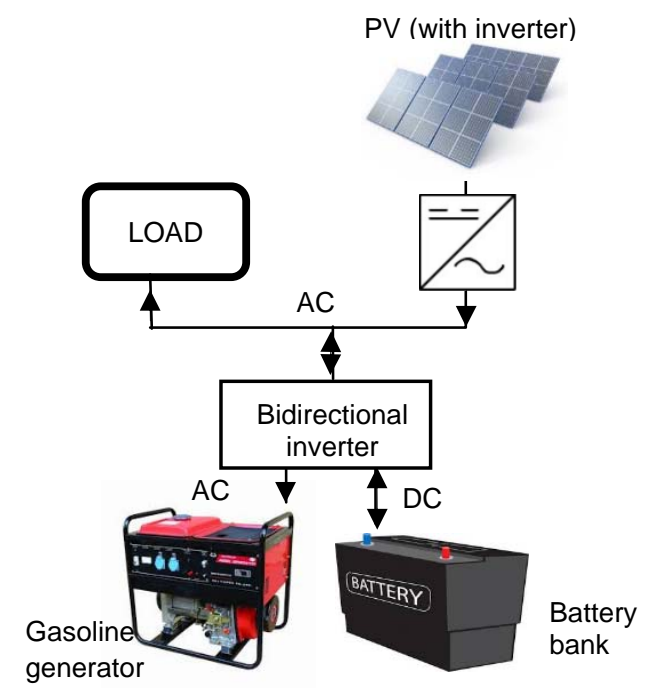

Fig. 2. PV-gasoline-battery system

The results are shown in Tables I and II, cases B1 and B2.

Results show that the model of Wang et al. is more optimistic than the other models. It must be considered that different authors essayed batteries of different manufacturers. Also, it must be considered that they are valid for relatively high C-rates, however in this case Crate is low (although higher than in case A). Anyway, for lower C-rates the lifetime should even be higher. Considering that around 564 full equivalent cycles (case B1) are performed per year, the value of 10.5 years predicted by the model of Grot, 2014 (around 6,000 full equivalent cycles) or even the value predicted by the model of Grot et al., 2015, that is, 12.8 years (around 7,200 full equivalent cycles) is more logical (but even it is very high) than the value predicted by the model of Wang et al., which is 18.1 years (this would imply more than 10,000 full equivalent cycles, which seems too optimistic and not realistic).

Similar reasoning can be done for the case B2, with 1,013 full equivalents cycles per year: the model of Grot, 2014 predicts 7.2 years (around 7,300 full equivalent cycles). The model of Grot et al., 2015 predicts 8.3 years (around 8,400 full equivalent cycles) and the model of Wang et al., predicts 12.1 years (more than 12,000 full equivalent cycles). The last one seems to be too optimistic.

\section{Conclusion}

It can be concluded that for PV-battery systems, where $\mathrm{C}$-rate is very low and the number of full equivalent cycles in the year is low, the lifetime of $\mathrm{LiFePO}_{4} /$ graphite batteries in stand-alone systems can be very high, even higher than the lifetime of the system. However, in systems with batteries of low capacity and gasoline or diesel generator, the lifetime can be much lower (in the case the cycle charging strategy is applied, the lifetime is lower than if load following strategy is used). Models predict different values for these cases. The model of Wang et al. is simple but seems to give too optimistic results. The model of Grot et al. 2015 is also simple but it seems to be more realistic, however, real experiments should be performed in order to confirm if any of the models studied brings satisfactory results.

\section{Acknowledgement}

This work was supported by the Ministerio de Economía $\mathrm{y}$ Competitividad of the Spanish Government under Project ENE2013-48517-C2-1-R.

\section{References}

[1] R.K. Akikur, R. Saidur, H.W. Ping, K.R. Ullah, Comparative study of stand-alone and hybrid solar energy systems suitable for off-grid rural electrification: A review, Renew. Sustain. Energy Rev. 27 (2013) 738-752. doi:10.1016/j.rser.2013.06.043.

[2] R. Dufo-López, J.M. Lujano-Rojas, J.L. Bernal-Agustín, Comparison of different lead-acid battery lifetime prediction models for use in simulation of stand-alone photovoltaic systems, Appl. Energy. $115 \quad$ (2014) 242-253. doi:10.1016/j.apenergy.2013.11.021.

[3] Wang, J. Liu, P, Hicks-Garner, J. Sherman, E. Soukiazian, S. Verbrugge, M. Tataria, H. Musser, J. Finamore, P. (2011) Cycle- life model for graphite-LifePO4 cells. Journal of Power Sources (196), 3942- 3948 
[4] Groot J. (2014) State-of -Health Estimation of Li-ion Batteries: Ageing Models. PhD Thesis. Chalmers University of Technology, Sweden.

[5] Groot, J. Swierczynski, M. Stan, A.I. , Kaer, S.K. (2015) On the complex ageing characteristics of high-power LiFePO4/ graphite battery cells cycled with high charge and discharge currents. Journal of Power Sources. (286) 475- 487 